\title{
The Hygienic Practices Involved in Three Game Meat Production Systems in South Africa Based on Environmental and other Independent Variables Van der Merwe $\mathbf{M}^{1 *}$, Hoffman $\mathbf{L C}^{2}$, Jooste $\mathbf{P J}^{3}$ and Calitz FJ ${ }^{4}$
}

${ }^{1}$ Tshwane University of Technology, Department of Environmental Health, Faculty of Science, South Africa

${ }^{2}$ Stellenbosch University, Department of Animal Sciences, Faculty of Agri Sciences, South Africa

${ }^{3}$ Tshwane University of Technology, Department of Biotechnology and Food Technology, Faculty of Science, South Africa

${ }^{4}$ ARC Biometry Unit, 1134 Park Street, Hatfield, South Africa

\begin{abstract}
Independent variables based on EU standards were used to compare environmental and other differences between three hunting systems, in terms of safety and quality. System 1 (Sys1) supplied game animals intended for the export market, System 2 (Sys2) supplied game carcasses intended for the local market, but was subjected to the training and application of specific hygiene and safety guidelines and System 3 (Sys3) game carcasses intended for the local market, but not subjected to the application of any health and safety guidelines. Although the process of obtaining a game carcass cannot be compared to the process followed in beef slaughterhouses, the export market standard was used as criterion of compliance and due to a total lack of standards or control for the local game meat market. The identified variables are situational and are based on procedural, environmental and other parameters as specified in the South African Veterinary Procedural Notices (VPN) that are specific guidelines linked to a regulation and in compliance with standards from countries of import.

The observations and tests conducted in the study showed a considerable difference in the independent variables tested for the three systems. It was however, concluded that Sys1 and Sys2 differed only with regards to the training component. It was concluded that the independent variables compared with these two systems questions the strict EU requirements and costly formal registered abattoirs when simplified and practical hygiene guidelines render carcasses with similar status.
\end{abstract}

Keywords: Game meat; Export; Local market; Environmental variables safety and quality

\section{Introduction}

The Game Industry in South Africa can be divided into two systems: on the one hand, the strict regulatory system for game meat intended for export purposes and on the other, an uncontrolled system applicable to game meat on the local market [1]. Van der Merwe et al. [2] researched the biological and food safety requirements of the European Union in terms of different game meat production systems in South Africa. In this study independent variables based on EU standards was used to further compare environmental and other differences between these systems, in terms of safety and quality. System 1 (Sys1) supplied game animals intended for the export market $(n=295)$ and cropping projects were conducted on $(\mathrm{n}=12)$ game farms with similar facilities, System 2 (Sys2) supplied game carcasses intended for the local market, but was subjected to the application of specific hygiene and safety guidelines $(n=165)$ on a specific game farm and System 3 (Sys3) game carcasses $(n=152)$ were intended for the local market, but were not subjected to the application of any health and safety guidelines and were conducted on $(n=12)$ game farms with similar facilities. Van der Merwe et al. [2] researched dependent variables, inter alia; carcass temperature and $\mathrm{pH}$, shelf-life as well as index and indicator bacterial counts for the three systems, in this study it has been deemed important to further report on the independent variables that were studied for the three systems. These variables are situational and are based on procedural, environmental and other parameters as specified in the South African Veterinary Procedural Notices (VPN). These legal guidelines include inter alia: farm registration for harvesting for the export market, requirements for the hunter, the required shot placement and bleeding method, requirements for the slaughter facility, a hygiene management system (HMS), and traceability compliance of the game meat. Furthermore, the training component i.e training of farm staff in basic meat hygiene and the training of a game meat examiner to conduct meat inspection at the game abattoir.

The VPN could be described as the most stringent part of the game meat hygiene legislation as it is based on EU standards and supports international management systems such as HACCP, ISO 9000 and ISO 14000. The VPN that were used for the independent variables described in the previous paragraph include inter alia: VPN/05/200809 i.e. the Standard for the registration or re-registration of a game farm for export purposes [3], VPN/08/2008-09 i.e. the Standard for the registration of hunters for harvesting wild game intended for export of game meat [4], VPN/09/2008-09 i.e. the Standard for the ante- and post-mortem meat inspection and hygiene at the point of harvest and hygiene control at point of game harvest and finally VPN/10/2008-09 i.e. the Standard for post-mortem meat inspection and hygiene control at game meat establishments [5]. Although a standard operating procedure (VPN/19/2009-01 i.e. the Standard relating to the National export residue control programme) is used by the export market as an assessment to determine which veterinary drugs with specified window periods and environmental chemicals or agricultural compounds must be singled out for surveillance in animal products, it is currently not

*Corresponding author: Van der Merwe M, Tshwane University of Technology, Department of Environmental Health, Faculty of Science, South Africa, Tel: 082498-0685; E-mail: marethavdm7@gmail.com

Received May 19, 2014; Accepted June 27, 2014; Published June 30, 2014

Citation: Van der Merwe M, Hoffman LC, Jooste PJ, Calitz FJ (2014) The Hygienic Practices Involved in Three Game Meat Production Systems in South Africa Based on Environmental and other Independent Variables. J Veterinar Sci Technol 5: 176. doi:10.4172/2157-7579.1000176

Copyright: () 2014 Van der Merwe M, et al. This is an open-access article distributed under the terms of the Creative Commons Attribution License, which permits unrestricted use, distribution, and reproduction in any medium, provided the original author and source are credited. 
compulsory for the local market and this has been documented in the abovementioned VPN nr.19 as such.

Traditionally hunting only takes place during the colder winter months from May to July, but the hunting season in South Africa has now been extended from March to August [1]. Furthermore game farms that have exempted status can hunt from January to December. VPN requirements restrict harvesting when the ambient temperature is more than $15^{\circ} \mathrm{C}$. In the winter season (hunting season) lower ambient temperatures $\left(15^{\circ} \mathrm{C}\right)$ are ideal for culling However, in terms of the practical application of such requirements; a study conducted by Deutz et al. [6] refuted the belief that high ambient temperatures could influence diseases in game animals and it is then suggested by the study that higher ambient temperatures could also facilitate harvesting with sufficient temperature control measures to prevent putrefaction of the carcasses.

The main aim of this study was to further strengthen the conclusion of van der Merwe et al. [2] and van der Merwe et al. [7], that safe game meat is ensured by good hygiene practices and effective meat hygiene training. Results from van der Merwe et al. [7] clearly indicated higher bacterial counts on game carcasses intended for the local market but not exceeding the legal standard and still within acceptable levels. The identification of the following inter alia independent variables (based on the standard as prescribed in the VPN) that can influence meat safety and quality (bacterial contamination) within the three systems were therefore conducted.

\section{Materials and Methods}

\section{A situational analysis of environmental and other independent variables relevant to the quality of game meat in three South African game meat production systems}

The following independent variables were addressed: veld type, shot placement and bleeding method, compliance to potable water standard and the slaughter facility. Further aspects investigated relate to a hygiene management system, traceability compliance and training of farm staff involved in the process of obtaining game carcasses. The variables discussed play an important role in ensuring high quality safe game meat for export purposes, but were also used to compare the three systems and to highlight areas of concern especially, in the uncontrolled supply of game meat to the local market. The analysis was done through documented observations of the three systems measured against the EU criteria of the abovementioned VPN. The three systems used in this study differed as follows in the hunting procedures that were followed to render game carcasses for export local markets.

System 1: In a ranching set-up such as System 1 (Sys1), the VPNs require the owner of the farm to apply in writing for a registration certificate issued by the Provincial Executive Officer (PEO) if he/she wishes to register or re-register a farm with the intent to harvest wild game animals for abattoirs approved to export wild game meat [3]. The application must be submitted to the State Veterinarian (SV) at least 14 days prior to intended harvest [8]. The State Veterinarian (SV) must explain in person to the owner what the implications are regarding the commitments and obligations the owner undertakes to honour the application. The farm must be located in a foot-andmouth disease free zone (without vaccination) of South Africa as recognized by the Office International des Epizooties (OIE), or otherwise outside any foot-and-mouth disease restricted area as communicated from time to time by the National Department of Agriculture, Forestry and Fisheries (DAFF) or as specified in the latest European Union Directives in the case of export to the European Union (EU).

Game animals may not be harvested in a hunting area where during the last 60 days there has been Animal Health restrictions due to an outbreak of a disease to which game animals are susceptible. The farm owner is compelled to not administer or provide access to production enhancers/growth stimulants, as specified, to any animal in the flock/ herd or allow such agents to be administered, or provided. The owner must then comply with the control measures imposed by the SV if an outbreak of a controlled animal disease should occur on the farm and provide a register of all treatments administered (following the controlled animal disease outbreak) for a minimum of 3 months. The Annual Livestock Report for all game animals on the farm must be kept up to date on a monthly basis and must provide the following details: Registration number of farm, farm name, year, month, stockbeginning total, plus: estimated natural population growth, plus: species of game including dates of arrival and origin of game brought in, minus mortalities, minus the following: stock sold, game harvested and finally the stock end-total [8].

A Post-Mortem Record file is required for all livestock and game on the farm and must provide the following details: registration number of farm, farm name, date of death, type of animal, reason for death/ diagnosis, official verification (including copies of post-mortem reports where applicable), and be checked by the Directorate Veterinary Services, Department of Agriculture, Forestry and Fisheries [9].

The hunter, after the owner, is the second role player in the harvesting team that will assist the game rancher in removing certain pre-planned parts of the game population, by culling those animals intended- and fit for human consumption [4]. The hunter/harvester in system 1 is expected to: provide a professional team of people consisting of well trained and experienced marksmen as well as trained and accredited veld abattoir personnel. The hunter must provide the right equipment to execute the task swiftly and professionally, such as suitable rifles, spotlights, specially equipped vehicles, a mobile field abattoir constructed according to state veterinary specifications, scales, sterilizers, generators, etc. In addition he must follow the correct prescribed veterinary procedures and ensure the highest levels of hygiene during the whole process. Correctly dressed and inspected carcasses are then transported within prescribed time schedules by refrigerated trucks to the abattoir. This is the stage when the crucial cold chain during meat transport and processing starts [8].

Game animals are shot from a vehicle, hoisted onto a frame or a ramp on the recovery vehicle and exsanguinated within 10 minutes by cutting the throat. Evisceration (removal of the "viscera" this is the fore stomachs \{rumen, reticulum, omasum, abomasum and intestines\}) and primary meat inspection follows at the temporary slaughter frame in the veld, which is equipped with slaughter frames, inspection hooks and washing facilities for sterilization. The undressed (unskinned) carcasses are refrigerated within 4 hours in a refrigerated vehicle and transported to the export abattoir.

System 2 and System 3: The hunter or the specific game farm in Sys2 is not registered (as in Sys1), but the hunter has successfully completed training in modules, that include procedures or techniques in meat hygiene during and after the process of hunting as well as a proficiency in meat inspection. These components are needed to ensure a carcass that is safe for human consumption $[5,10,11]$. However in Sys3 the hunter's intention is to obtain a trophy for his collection. Shot placements and correct slaughtering or dressing methods are not 
prioritized as the thrill of the hunt is the main goal and not the quality or safety of the meat [1].

Animals are shot from vehicles and on foot, depending on the hunt and the hunter`s preference. Trophy carcasses are not exsanguinated to prevent damage to the trophy but sometimes bleed internally when damaged by thoracic shot or when the chest stick method is used to promote internal bleeding. Evisceration usually takes place in the veld and the eviscerated material is left for scavengers and vultures. Carcasses are transported to a slaughter facility on the farm after photos and other traditional procedures to highlight the hunt are completed. Carcasses are caped (for trophy purposes) or skinned and hung to dry before refrigeration (usually for 10-12 hours). However, the difference between Sys2 and Sys3 is that basic meat hygiene principles and the approved meat inspection procedure (according to the Meat Safety Act 40 of 2000), were applied to hunted carcasses in Sys2.

\section{Specific techniques or methods employed}

The criteria used for all independent variables were based on the VPN requirements as previously specified [3-5]. The dependent variables reported on in this study included the following that link with the results from the study conducted by van der Merwe et al. [2] on bacterial differences between the hunting/harvesting systems:

- Veld type: Only two criteria were considered in terms of accessibility to carcasses for transportation to the slaughter facility namely: open or bushy terrain. Dense areas with trees and hills were classified as "bushy" and open savannah areas with mainly grass and smaller shrubs were classified as "open". A refined definition of the above criteria was used for each carcass. Extended time periods during the recovery of carcasses could result in higher bacterial counts due to temperature, physical damage and soil contamination.

- Shot placement: Quantified by observation of the part of the body in which the shot was placed namely in the head, in the front quarter (including the neck) or in the hind quarter (including the backbone and gut). Poor shot placement i.e. abdominal shots could contaminate the carcass meat with bacteria and not fit for human consumption.

- Bleeding methodology: Data was obtained by observation and recording of the time to bleed from shooting as well as the method used (if any) compared against criteria from the VPN. Poorly bled carcasses will have short shelf life, darker colour and higher bacterial counts than well bled carcasses [7].

- Taking and testing of water samples: Sampling results were obtained on Sys1, Sys2 and Sys3 farms. The SANS 241 standard for potable water is: $E$. coli count per $100 \mathrm{ml}=0$ and coliform count per $100 \mathrm{ml} \leq 10$. Water samples were taken aseptically from taps in the slaughter facility (water from boreholes) in sterilized $250 \mathrm{ml}$ glass bottles provided by the laboratory, placed in coolers and submitted to the laboratory together with the surface swabs taken from carcasses on the ranch. Samples were transported on ice (controlled temperature below $7^{\circ} \mathrm{C}$ ) to the SANAS accredited laboratory in Polokwane. Water not on standard could contaminate meat and increase bacterial levels.

- Traceability of carcasses: All meat produced for commercial purposes (export adhere to the VPN and local must comply to food regulatory legislation [12]) must be traceable

- Level of training: Proof of qualifications and meat hygiene training were requested to determine compliance of the inspection staff for the export and local market and additionally, basic meat hygiene for staff on the farms producing for Sys2

- Compliance in \% of meat inspection and registered slaughter facilities: Based on observations recorded during harvesting and hunting projects out of the total number of carcasses monitored in each system.

\section{Statistical procedures}

A total of 625 carcasses were observed and counts taken, of which 612 were used for the final data analysis. $\mathrm{R} \times \mathrm{C}$ contingency tables were constructed (a two way table with observations, counts and percentages) and the Chi-square test was performed to test for independence and similar patterns between the different rows. This was done using SAS statistical software version 9.2

\section{Results and Discussion}

\section{Veld types}

The VPN do not require description or specification of the veld type and consequently game farms registered for export, can be situated in various regions or environments including the following: semi-desert areas in the Northern Cape, savannah veld in the Free State, mountainous terrain in the eastern Cape and the very dense bush in the Provinces of Limpopo and North West. The veld type for Sys1 was mainly open veld as harvesting for export purposes is conducted mainly on springbok that prefer open savannah regions [13]. Sys 1 preferred two and three digit numbers of game units to be harvested at a time, to increase the profit margin as transportation and the costs for harvesting teams and equipment are high $[14,15]$. For this reason, open areas were preferred to accommodate big harvesting teams with their equipment as well as to facilitate the harvesting process [13]. Sys2 and Sys 3 conduct trophy as well as biltong hunting and therefore vast regions, regardless of the topography, are covered to hunt game on these types of ranches [16]. It is however recommended that an open hunting area could facilitate shorter time periods for carcass recovery and less transportation time to the slaughter facility and the further cooling process of the carcass. The predominant veld type in Sys1 was open areas in Sys2 bushy veld and Sys 3 an equal combination of the two. However, for each carcass a more refined definition was used in terms of the specific area on the farm where the animal was hunted. Low velocity calibre rifles could be used in bushy areas to minimize the damage to the carcass (when shooting distances are less than $120 \mathrm{~m}$ ). According to Shack [8] in desert areas long distances could be applicable and fast heavy premium spritzer bullets should be used. He noted that; when hunting bigger animals in open plains, heavy bullets with good ballistic co-efficiency should be used whereas heavy bullets will destroy smaller animals. Hunters have to use different calibres that suit the area as well as the animal being hunted. Difficult terrain will have a negative influence on the shot placement (damage to the carcass) bleeding time, evisceration time and the time to chilling. All such factors will influence and ultimately determine the bacterial safety and quality of the meat.

The veld type will also influence the recovery time of the hunted carcass (in terms of accessibility and carcass transportation) which could consequently, have an effect on the hygiene and quality of the meat. However, all three systems are compelled to hunt or harvest in different veld types to obtain the preferred trophy (Sys2 and 3) or an economically viable number of animals for cropping (Sys1). In Figure 1 the results are shown for the veld type in the three systems. 


\section{Veld Type}

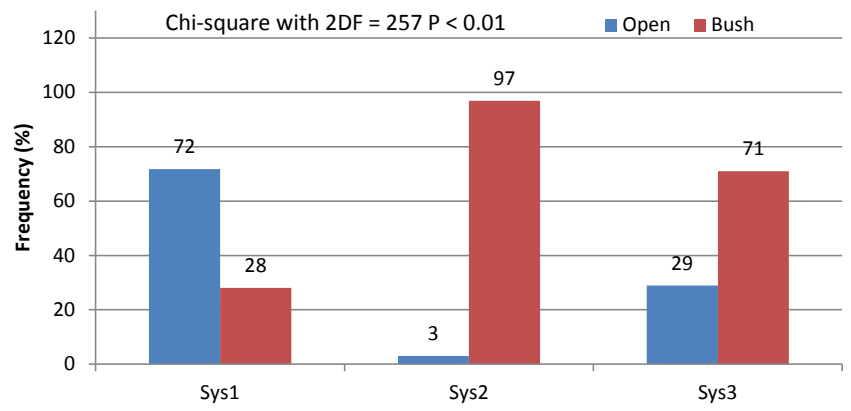

Figure 1: Veld types on which harvesting and hunting occurred in the three systems.

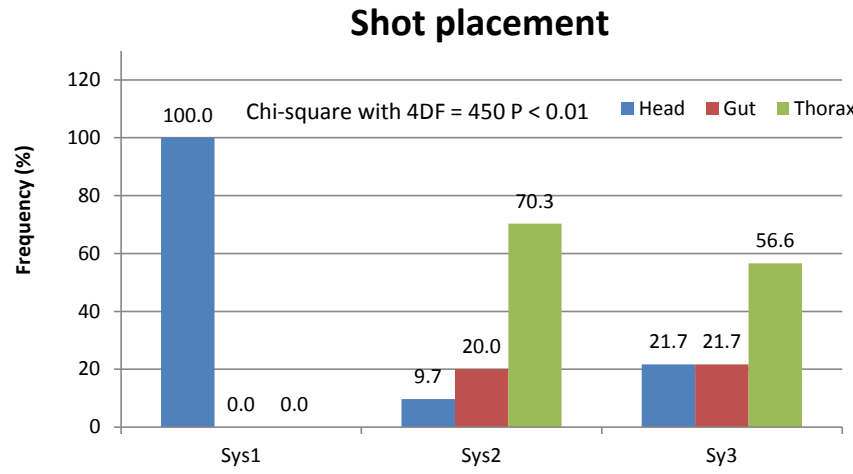

Figure 2: Shot placements in hunted game on the ranches representing the three systems.

Differentiation has only been made in this section between open and bushy, but veld types could also differ from steep hills to sandy and rocky. For the purpose of this study and to determine the accessibility, only the open and bushy criteria were used. On the Sys1 ranches, harvest was mainly conducted in open veld to prevent time delays in obtaining game carcasses and because it was the habitat of springbok that is the preferred specie for countries of import. The ranch that represented Sys2 was situated in the North West Province of South Africa and the veld type was predominantly bushy. On the Sys 3 ranches an equal combination of open and bushy veld types occurred.

\section{Shot placement}

Shot placements are regarded by the export market as the starting point of a safe carcass for human consumption. According to Hoffman and Bigalke [17] poor shot placements will not only result in bacterial contamination but also in poor carcass yield. Marksmen in Sys1 are punished in terms of their remuneration when failing the required head shots. In Sys1, carcasses with front and hind quarter shots are not approved for export purposes [5,18].

In Sys 2 and Sys 3 the shot placement and the meat is not prioritized, the hunt itself being granted top priority [1]. Therefore, less than ideal shot placements (Figure 2) seem to be the norm. In support of Sys2 and Sys3, the application of an ideal shot placement was refuted by Urquhart and Mckendrick [19] and they recommended that factors such as animal welfare should rather be considered and that such shots could render carcasses fir for human consumption.

System 1: In this ranching system the harvesting of game for export purposes may only be done by a registered hunter and must furthermore be done in such a way that it is reliably expected to cause immediate death; and is in accordance with animal welfare. Head shots are used and game killed with thoracic shots is subject to secondary meat inspection so that a decision can be made on possible condemnation (veterinary approval). Abdominal shots must be condemned for export purposes and cannot be transported to establishments together with approved head shot carcasses. The VPN [4] and draft Game Regulations (to be promulgated under the Meat Safety Act, Act 40 of 2000) stipulate that only head shots are approved for commercial purposes and that any wounded animals requiring a second shot be condemned if a time period of more than 10 minutes is exceeded after the first shot. The desirability to cause instant death with minimum injury or pain to the animal and the ideal to prevent high levels of stress and low levels of muscle glycogen are all motivational issues in this requirement.

Systems 2 and 3: The hunters in ranching systems Sys2 and 3 are not registered, but are competent hunters, compliant to the National Conventional Arms Control Act 41 of 2002 and shot placement is relevant only to the trophy required and the veld type. In this scenario; a thoracic shot is regarded as a safe shot in terms of animal welfare [8]. Abdominal shots may take place when trophy hunting and when hunting in dense bushes with poor visibility. Urquhart and Mc Kendrick [19] concluded that head shooting could result in wounded animals and more consideration should be given to animal welfare rather than marksmanship. However, for trophy purposes shot placements are sometimes intentionally gut and hind quarter to facilitate cape or full mount trophies. Although this is not desirable in meat production, the possible conditional utilization of trophy carcasses in the commercial market was recommended by Hoffman [20]. Trophy hunting, when conducted in difficult hunting terrain or with poor visibility for a clear shot usually require thoracic and even hind-quarter (gut) shots. These shot placements are considered by the export market to result in high $\mathrm{pH}$ readings and poor bleeding reports. However, game carcasses with thoracic shots could be approved for commercial purposes after secondary inspection and approval by a veterinarian.

In Figure 2 the different shot placements used in the three systems are shown. On the Sys1 ranch, head shots were compulsory and marksmen in the export trade are paid according to their compliance percentage [10]. Game shot on Sys2 and Sys3 ranches showed a high incidence of shot placement in the thorax as well as in the hind quarter (abdomen/gut).

\section{Bleeding (exsanguination)}

The bleeding method and time is specified for Sys1 and no other bleeding methods are approved for export. However, successful bleeding has been observed with immediate post-mortem evisceration of carcasses (Sys2 and Sys3) as well as that due to internal bleeding with thoracic shots (when vital organs are damaged). Recorded, scientific proof of throat slitting as preferred method of bleeding is not available, but is an international norm suggested by the OIE, FAO and Codex Alimentaruis Commission based on the slaughtering process of domesticated animals when the animal is not killed but stunned and the pumping action of the heart ensures preferred complete bleeding through the severed throat [21]. Effective bleeding will enhance the shelf life of the meat and lowered bacterial levels [2]. Sys2 and Sys3, as mentioned, make use of several other methods of bleeding (for example sticking of the arteries to enhance bleeding into the thoracic cavity to not damage the cape) and not always within the required 10 minutes according to the VPN. 
System 1: Game hunted on Sys1 ranches must according to the VPN be bled within 10 minutes of being shot. Sufficient literature is not available on bleeding volumes for every species, neither is literature available with regard to the time needed for "good bleeding". Category $\mathrm{B}$ animals (blue wildebeest and eland) are compared to domesticated bovine animals to determine the bleeding volumes [10]. Domesticated pigs or sheep are similarly used in comparison with category $\mathrm{C}$ animals such as impala and springbok for their blood volumes. Visually noted observations, during the study, of the dressed carcasses at export harvesting operations as well as planned trophy hunts, indicated that game animals are bled as effectively as their counterparts in red meat abattoirs. Bleeding is done by means of severing the jugular vein and carotid artery on either side of the neck (throat slitting). Bleeding must be done whilst the carcass is in the same position as during transportation [5]. The bleeding knife used must be cleaned and sterilised with water at $82^{\circ} \mathrm{C}$ or via a chemical method of sterilisation, approved by the Veterinary Authority [18].

Systems 2 and 3: On Sys2 and 3 ranches, hunted animals are not always bled within 10 minutes of shooting or with the required method of throat slitting. It can however be argued that bleeding is equally effective when, for example, the carcass is immediately eviscerated in the field and the femoralis artery is severed. Also, bleeding of trophy carcasses usually occurs internally when the vital organs are damaged by the shot (especially when a thoracic shot is used) and such cases have been shown to bleed effectively as blood accumulates in the thoracic cavity and is released during the slaughtering process [10]. In Figure 3 the bleeding method used by the hunters in the three systems are shown as a percentage of the animals shot.

\section{Bleeding method}

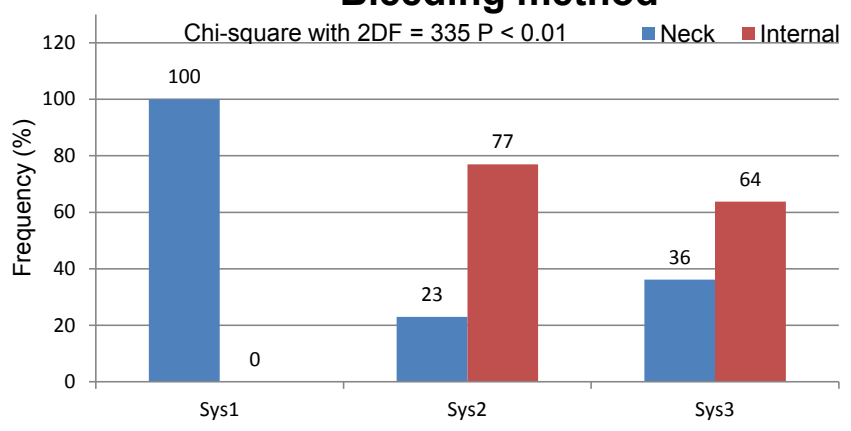

Figure 3: The different bleeding methods used by the three systems respectively.

\section{Water compliance SANS 241}

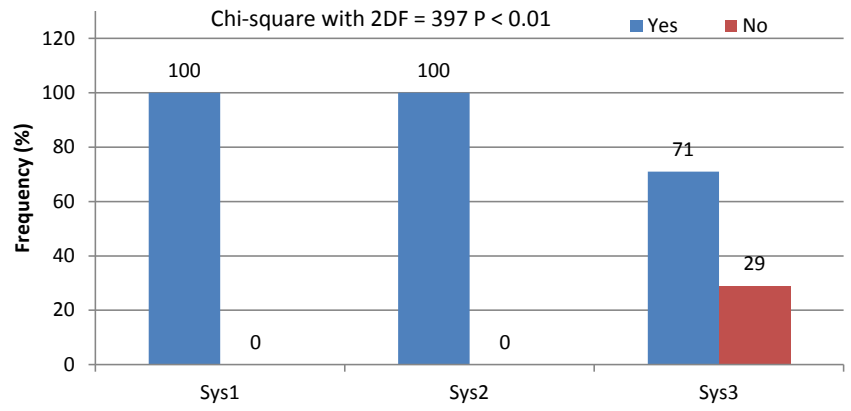

Figure 4: The compliance of potable water (SANS, 2005) tested on ranches representing the three systems.

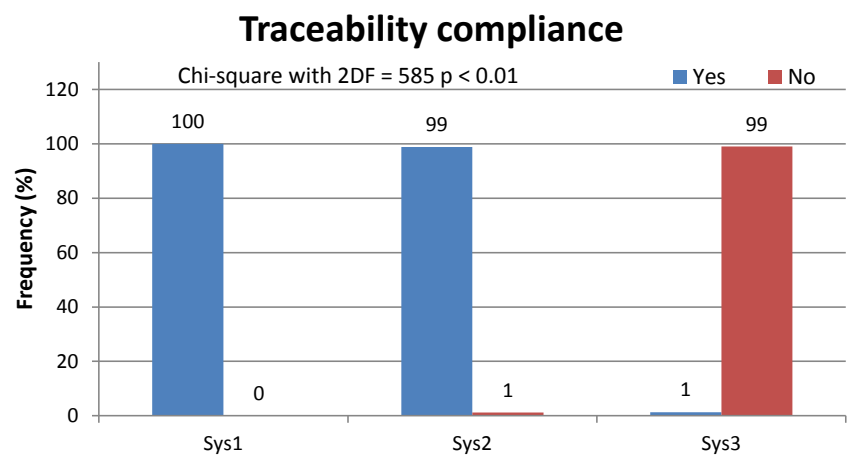

Figure 5: Traceability of game carcasses from ranches in the three systems.

\section{Water sampling}

VPN 10 [22] requires proof of potable water according to SANS 241 [12]. For the purpose of this study the focus was on the bacteriological compliance of the water. Sys1 and Sys2 complied with VPN10, but 29\% of the farms in Sys 3 did not comply (Figure 4). Taking into consideration the dry process when game animals are slaughtered, a statement can be made that potable water is not as applicable in a game slaughter facility as in a red meat abattoir with big volumes of effluent and where water is used to wash carcasses, surfaces and floors. However, potable water is required for the washing of hands, surfaces and sterilization of equipment to lower bacterial contamination and should therefore be adhered to during the slaughter process [23].

System 1: According to the VPN Standard for post-mortem meat inspection and hygiene control at game meat establishments [9], the ranch owner is responsible to provide proof of potable water available on the ranch registered for export harvesting. Furthermore, the abattoir owner must ensure that water used in the slaughter facility/abattoir is potable, as stipulated by the South African National Standards (SANS) 241 [12]. In the abattoir, records of microbiological and chemical water test results must be available. Such results were recorded in this study for Sys1. For the process of obtaining the carcasses on the farm, potable water and facilities must be provided for the sterilisation of the knives and equipment at $82 \mathrm{C}$ or any other means of sterilization approved by the Veterinary Authority.

Systems 2 and 3: Although the slaughter process of game animals is inherently a very dry process and the amount of water used in the slaughter facility/abattoir is minimal, water tests were conducted on all the ranches in Sys2 and Sys3 to test compliance with the SANS 241 standard for potable or drinking water (bacteriologically compliant) and to rule out possible contamination from water sources. In Figure 4 the results of the water samples taken are shown for the three systems. As required by the VPN the farms that were registered for export harvesting in Sys1 complied. With regard to Sys2 all carcasses were from one farm and the results were also in accordance. However, game farms make use of boreholes and river water and this could result in possible water contamination when such uncontrolled water sources are utilized in the slaughter process.

\section{Traceability}

In Figure 5 the traceability of carcasses in the three systems are given in percentage of the animals hunted. According to the VPN this is required for Sys1, but according to the new regulations is also required for any carcass in the local commercial market. Sys 3 , ranches however, do not have any recording systems available. In Sys2, $1 \%$ of the 
carcasses were recorded but were not traceable due to trophy carcasses that could not be utilized for their meat. In Sys3, 1\% of the carcasses were traceable when records were kept on request from the professional hunters or outfitters. The documented recording system is discussed in more detail under section 6.3.1.9 under the heading "Registration of a game farm for meat export". Traceability is required by the EU and Sys 1 is consequently compelled to ensure traceability of all meat [12]. Traceability in terms of animal disease control is very important and required for all foodstuffs on the commercial market [24]. Traceability requires a recorded system of documentation from the production farm through to the consumer [25]. The Sys2 ranch had a recording system on the farm, but the documentation was sometimes not completed by the processors or end-buyers since the legal requirement is not compulsory yet for the local market [24]. Sys3 did not comply with traceability (Figure 5) as no records are kept on the farm or by the buyers of the meat.

\section{Level of training for meat inspection}

System 1: VPN 09 [5] stipulates that meat inspection must be performed by a qualified meat inspector (qualified to South African Quality Assurance level 4) for the purpose of export. However, the physical inspection is conducted on the slaughter floor by a meat examiner (qualified to South African Quality Assurance level 3). The meat examiner conducts his inspection under the supervision of a meat inspector or a veterinarian to assist with secondary inspections and final decisions on detained carcasses [5]. The inspection procedure is specified in the VPN and the MSA [5] to ensure safe carcasses with good shelf life to the meat markets.

System 2: The function performed in Sys2 by the meat examiner is then in compliance with a supervision deficit of a game meat inspector or a veterinarian [5]. However, carcasses can be detained until a secondary inspection has been conducted by a game meat inspector or a veterinarian and a decision made to condemn or approve the carcass. Arrangements could also be possible based on electronic photo's send to veterinarians for diagnosis in cases of remote farms. On Sys2 ranches game meat inspection was conducted on all carcasses by hunters qualified as game meat examiners, the inspection was done according to the MSA and VPN as specified in Sys1, not by a "game meat inspector" but by a trained "game meat examiner". This lower qualification level is more affordable and viable on game farms producing meat for the local market. This finding of suffice training was furthermore confirmed by Bekker et al. [24].

System 3: In Sys3 no meat inspection is conducted as there is no legislation applicable except for export game meat (Sys1) that requires inspection. Inspection will not be required if a few animals are culled for own consumption, yet large numbers of animals sold through super markets have to adhere to standards as prescribed in the Meat Safety Act, 40 of 2000. In Figure 6 the different levels of training are shown for the three systems. Sys 1 is compelled to have meat inspection by a qualified meat inspector, Sys 2 conducted meat inspection by a game meat examiner and in Sys3 no inspection was conducted on any of the carcasses.

\section{Meat inspection, training and slaughter facility}

System 1: The abattoir is a specialized plant or slaughter house where carcasses of the different game categories A, B and C are skinned and prepared for the processing plant. Abattoirs from which animals are exported are built to certain specifications and undergo stringent testing and scrutiny before being certified by State Veterinary and European Union authorities as being fit for exportation purposes. Qualified game meat inspectors conduct inspection on all carcasses and secondary inspections are conducted by qualified veterinarians. Basic meat hygiene training is however not a requirement. The game abattoir is mentioned only briefly as it falls outside the scope of the study. Nevertheless, the draft Game Regulations stipulate that a registered game abattoir must be available on the game farm if commercial use is the intension.

Systems 2 and 3: In the study of van der Merwe et al. [2] a list of all the registered abattoirs for export and local purposes has been provided and clearly shows the deficit in terms of sufficient facilities for the demand. Basic and practical cost-effective slaughter facilities are available on most hunting farms, but such facilities are sometimes not on par with the requirements of the Meat Safety Act 40 of 2000. The slaughter facilities in Sys2 and Sys3 were not registered with the Department of Agriculture, Forestry and Fisheries (DAFF). However, in Sys2 all staff involved in the slaughter process are trained in basic meat hygiene that include modules on personal hygiene, sanitation, pest control and waste removal (condemned material). In Figure 7 a comparison is made between the three systems illustrating compliance in terms of game meat inspection (yes or no), the training of the slaughter staff in basic meat hygiene (yes or no) and the registration of the slaughter facility with DAFF (yes or no). Sys1 and Sys2 presented with full compliance (100\% Yes) with all mentioned criteria. Sys 3 presented with (100\% No) for non-compliance [25].

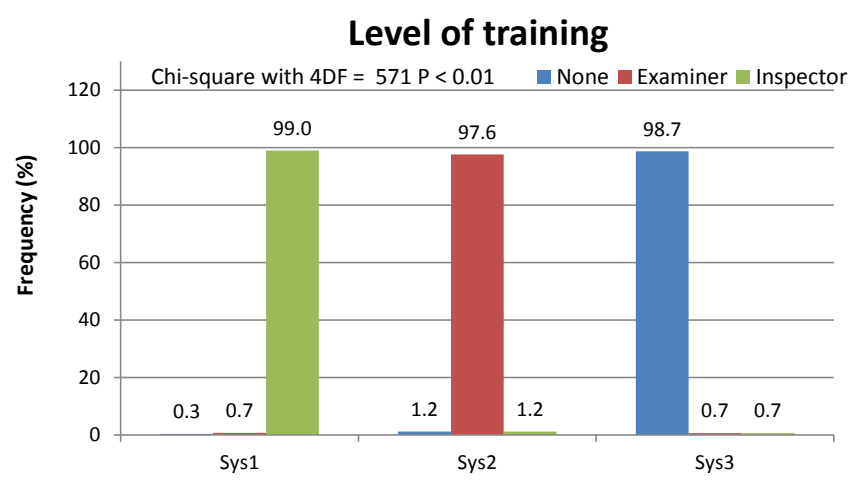

Figure 6: The level of training for meat inspection on ranches in the three systems.

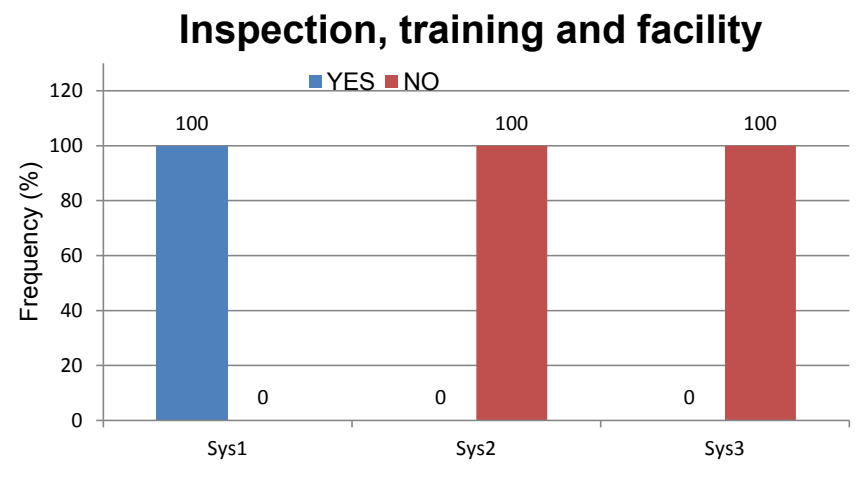

Figure 7: The compliance in percentage of meat inspection conducted, game meat hygiene training and a registered slaughter facility for game carcasses in the three systems. 
Citation: Van der Merwe M, Hoffman LC, Jooste PJ, Calitz FJ (2014) The Hygienic Practices Involved in Three Game Meat Production Systems in South Africa Based on Environmental and other Independent Variables. J Veterinar Sci Technol 5: 176. doi:10.4172/2157-7579.1000176

\section{Conclusions}

The observations and tests conducted in this study clearly show there is a considerable difference in the independent variables tested for the three systems in this study. In most cases Sys2 and Sys3 had similar results due to the same uncontrolled hunting process. The facility registration was only honoured by Sys 1 and the facilities in Sys2 and 3 were not registered or audited by DAFF officials for compliance with the Meat Safety Act. Although formal building structures are legally required to enhance the process of hygiene and cleaning as well as the safe disposal of offal [23], it was shown that basic unregistered slaughter facilities (can be compared to the slaughter frames of the export market in the field that does not require registration) can render game carcasses safe for human consumption that are within acceptable bacterial standards specified by van der Merwe et al. [2].

It is then concluded that an identified difference between Sys 1 and Sys 2 could be the training component (basic meat hygiene training) and that the independent variables compared with these two systems questions the necessity for similar strict formal requirements for the local market than that of the export market. The results from the study conducted by van der Merwe et al. [2] on higher bacterial counts (although within approved limits) on the carcasses intended for the local market in comparison with carcasses from the export market, the focus should be on producing safe game meat using safe water, adhering to requirements pertaining to disease control areas and not necessarily adhering to inter alia ideal shot placements, bleeding time and method. In addition, Veary [26] found that the effect of delayed evisceration on the microbial quality of the meat was insignificant and further strengthens the latter argument on futile time specifications as required in the VPN and draft Game Regulations.

It is recommended that game farm workers, hunters and professional hunters or outfitters on farms producing game meat for the local market, should be trained in basic meat hygiene and meat examination to enhance community upliftment on the one hand but more importantly to ensure a high standard of meat hygiene on the other hand and prevent unsafe game carcasses from becoming commercially available.

\section{References}

1. Van der Merwe M, Jagals PJ, Hoffman LC (2009) Health-related bacterial conditions on game carcasses intended for the local South African market compared to conditions on carcasses intended for export markets.

2. Van der Merwe M, Jooste PJ, Hoffman LC (2011) Application of European standards for health and quality control of game meat on game ranches in South Africa. J S Afr Vet Assoc 82: 170-175.

3. South Africa: National Department of Agriculture, National Directorate Animal Health (2010b) Standard for the inspection of wild game farm for the export of wild game meat: VPN/05/2010-01. Government Printers, Pretoria

4. South Africa: National Department of Agriculture. Forestry and Fisheries (2010a) Standard for the registration of game harvesters for harvesting wild game intended for export of game meat: VPN/08/2010-01. Government Printers, Pretoria

5. South Africa: National Department of Agriculture. National Directorate Animal Health (2010c) Standard for the ante- and post-mortem meat inspection and hygiene at point of harvest: VPN/09/2010-01. Government Printers, Pretoria

6. Deutz A, Guggenberger T, Gasteiner J (2011) Influence of climate change on disease of wild animals. In: Paulsen P, Bauer A, Vodnansky M, editors. Game meat hygiene in focus. Springer Verlag, pp. 157-72.

7. Van der Merwe M, Hoffman LC, Jooste PJ, Calitz FJ (2013) The hygiene practices of three systems of game meat production in South Africa in terms of animal class and health compliance. Meat Sci 94: 145-152.
8. Shack W (2008) Wildlife meat production. In Bothma, J du P (ed), Game ranch management. 4th ed. Pretoria, South Africa: Van Schaik, 547-551.

9. South Africa: National Department of Agriculture. National Directorate Anima Health (2007) Standard for post-mortem meat inspection and hygiene control at game meat establishments: VPN/10/2007-01. Government Printers, Pretoria.

10. Bergh T (2005) Personal Communication; Deputy Director: Department of Agriculture Forestry and Fisheries. In Pretoria, South Africa.

11. Bergh T (2007) Meat inspectors manual game. Department of Agriculture Forestry and Fisheries, Republic of South Africa. Pretoria: Government Printers.

12. South Africa: National Department of Health (1972) The Foodstuffs, Cosmetics and disinfectant Act 54 of 1972 , Regulations relating to the Labeling and Advertising of Foodstuffs as part of the Act, published in August 2002 to become law in 2004. Regulation R962 governing: General hygiene requirements for food premises and the transport of food.

13. Ebedes H, Meyer SGH (2008) Venison for Export. In Bothma, J.du P. (ed) Game ranch management. 4th ed. Pretoria, South Africa: Van Schaik pp. 547 551.

14. Bothma J, Du P (2004) Game Ranch Management. 4th ed. Van Schaik, Pretoria.

15. Kruger A (2006) Personal communication; Veterinarian: Mosstrich game abattoir, Port Elizabeth, South Africa.

16. Van Der Merwe P, Saayman M, Krugel W (2006) Economic contribution of biltong hunters in South Africa, paper presented at the 61st International Atlantic Economic Conference, 15-19 March, Berlin.

17. Hoffman LC, Bigalke RC (1999) Utilising wild ungulates from southern Africa for meat production: potential research requirements for the new millennium. In: Congress of the Wildlife Management Association of South Africa. George, South Africa.

18. South Africa (2002) Department of Agriculture. Animal Health Act 7 of 2002 Government Gazette, 23675.

19. Urquhart KA, McKendrick IJ (2006) Prevalence of 'head shooting' and the characteristics of the wounds in culled wild Scottish red deer. Vet Rec 159 : 75-79

20. Hoffman LC (2009) Comparing the effects on meat quality of conventional hunting and night cropping of impala (Aepyceros melampus) South African Journal of Wildlife Research, 39: 39-47.

21. Herenda A, Chambers PG, Ettriqui A, Seneviratna P, Da Silva TJP (2000) Manual on meat inspection for developing countries. 2nd ed. OIE Food and Agriculture Organization of the United Nations Rome, 1994 FAO Animal production and health paper 119 .

22. South Africa (2010e) National Department of Agriculture. National Directorate Animal Health. 2010e. Standard for post-mortem meat inspection and hygiene control at game meat establishments: VPN/10/2010-01. Government Printers, Pretoria, South Africa

23. Sprenger RA (1999) Hygiene for Management. 8th ed. South Yorkshire, UK Highfield.

24. Bekker JL, Hoffman LC, Jooste PJ (2011) Knowledge of stakeholders in the game meat industry and its effect on compliance with food safety standards. Int J Environ Health Res 21: 341-363.

25. South Africa (1972) National Department of Health. The Foodstuffs, Cosmetics and Disinfectant Act 54 of 1972. Pretoria, South Africa: Government Printers.

26. Veary CM (1991) The effect of three slaughter methods and ambient temperature on the $\mathrm{pH}$ and temperatures in springbok (Antidorcas marsupialis) meat. Mmed Vet (hyg) thesis. Faculty of Veterinary Science, University of Pretoria, South Africa. 